\title{
Prognosis of Patients Victim of Spontaneous Subarachnoid Hemorrhage: A Comparison between Radiologic Scales
}

\section{Prognóstico de pacientes vítimas de hemorragia subaracnóidea espontânea: comparação entre escalas radiológicas}

\author{
Luiza Maria Dias Abboud Hanna1® ${ }^{1}$ Sarah Eloisa Biguelini ${ }^{1}$ Francisco Alves de Araujo Junior ${ }^{1}$ \\ Anderson Matsubara ${ }^{2}$ Pedro Helo dos Santos Neto ${ }^{3}$ \\ 1 Faculdades Pequeno Príncipe, Curitiba, Paraná, Brazil \\ 2 Hospital Universitário Evangélico Mackenzie, Curitiba, Paraná, Brazil \\ 3 Faculdade Evangélica Mackenzie do Paraná, Curitiba, Paraná, Brazil \\ Arq Bras Neurocir 2020;39(1):1-4 \\ Address for correspondence Luiza Maria Dias Abboud Hanna, \\ Rua Coronel Pedro Scherer Sobrinho, Cristo Rei, 152, Bloco 4A, \\ Apartamento 211, Curitiba, Paraná, Brazil \\ (e-mail: luizamariahanna@hotmail.com).
}

\begin{abstract}
Keywords

- intracranial vasospasm

- subarachnoid hemorrhage

- aneurysm

- prognosis

Resumo

Objective To analyze the population and the early mortality rate (up to thirty days) of patients victim of spontaneous subarachnoid hemorrhage (SAH) according to the Hunt-Hess clinical scale and the Fisher and modified Fisher radiological scales.

Materials and Methods We analyzed 46 medical records and skull computed tomography (CT) scans of patients with spontaneous SAH admitted between February 2014 and December 2017 at Hospital Universitário Evangélico Mackenzie, in the city of Curitiba, state of Paraná, Brazil. The method of the study was exploratorydescriptive, transversal and retrospective, with a quantitative approach. We analyzed epidemiological (gender, age), clinical (life habits, pathologies, Glasgow coma scale and Hunt-Hess scale) and radiological (Fisher and modified Fisher scales) variables, and the Hunt-Hess and the Fisher scales were correlated with risk of death. The data was submitted to statistical analysis considering values of $p<0.05$.

Result There was a higher prevalence of spontaneous SAH among women (69.5\%), as well as among patients aged between 51 and 60 years (34.7\%). Regarding the grades on the scales, there was higher prevalence of Fisher 4 , Modified Fisher 4 and Hunt-Hess 2. Evolution to death was higher among women (76.4\%) and patients aged between 61 and 70 years $(35,2 \%)$.

Conclusion Mortality was higher among patients classified as Fisher 3, Modified Fisher 4 and Hunt-Hess $\geq 3$. The Fisher scale is better than the modified Fisher scale to assess the risk of mortality.

Objetivo Analisar o perfil epidemiológico, assim como a taxa de mortalidade precoce (até 30 dias do internamento) de pacientes vítimas de hemorragia subaracnóidea espontânea (HSAE) de acordo com a escala clínica de Hunt-Hess, e com as escalas radiológicas de Fisher e de Fisher modificada.
\end{abstract}

received

August 25, 2019

accepted

September 27, 2019
DOI https://doi.org/

10.1055/s-0039-3399537. ISSN 0103-5355.
Copyright ( $\odot 2020$ by Thieme Revinter

Publicações Ltda, Rio de Janeiro, Brazil
License terms

(c) $(1) \$$ 


\author{
Palavras-chave \\ - vasoespasmo \\ intracraniano \\ - hemorragia \\ subaracnóidea \\ - aneurisma \\ - prognóstico
}

Materiais e Métodos Realizamos análise de 46 prontuários e exames de tomografia computadorizada (TC) de crânio de pacientes vítimas de HSAE no período de fevereiro 2014 a dezembro 2017 admitidos no Hospital Universitário Evangélico em Curitiba-PR. O método de escolha foi o exploratório-descritivo, transversal e retrospectivo, com abordagem quantitativa. Foram analisadas variáveis epidemiológicas (idade, sexo), clínicas (hábitos de vida, patologias, escala de coma de Glasgow e escala de Hunt-Hess) e radiológicas (escala de Fisher e de Fisher modificada), e as escalas de Hunt-Hess e de Fisher foram correlacionadas com o risco de óbito. Os dados foram submetidos a análise estatística considerando valores de $p<0,05$.

Resultados Houve maior prevalência de HSAE entre mulheres (69,5\%), assim como entre pacientes com idade entre 51 e 60 anos (34,7\%). Entre as escalas, houve maior prevalência nas graduações Fisher 4, Fisher modificada 4 e Hunt-Hess 2 . Os pacientes que mais evoluíram a óbito foram os do gênero feminino (76,4\%), e também aqueles com idade entre 61 e 70 anos (35,2\%).

Conclusão A mortalidade foi maior em pacientes classificados com Fisher 3, Fisher Modificado 4 e Hunt-Hess $\geq 3$. A escala de Fisher é melhor do que a de Fisher modificada para avaliar o risco de mortalidade.

\section{Introduction}

Spontaneous subarachnoid hemorrhage (SAH) caused by rupture of a cerebral aneurysm has a mortality rate of $48 \%$ in patients older than 60 years of age, whereas in younger individuals, the rate is of $19 \%{ }^{1,2}$ Furthermore, $40 \%$ of the hospitalized patients die within a month of the event. Vasospasm, which occurs in $20 \%$ to $40 \%$ of the patients, is considered the most frequent complication in cases of spontaneous SAH. ${ }^{3}$ The Fisher scale is widely used for the classification of spontaneous SAH, and it is based on the findings of skull computed tomography (CT); however, it fails to grade the risk of symptomatic vasospasm in those patients. The modified Fisher scale appears to have a higher predictive power for the occurrence of this complication. ${ }^{3}$ Patients with SAH can also be classified according to their surgical risk, through the scale developed by Hunt \& Hess, which is based on the clinical presentation of the patients. ${ }^{4}$

The objective of the present study is to evaluate the morbidity and mortality of individuals with spontaneous cerebral aneurysm rupture, based on the aforementioned scales, with the purpose of assisting the therapeutic management of these patients and comparing both scales according to their efficacy while predicting the occurrence of vasospasm.

\section{Materials and Methods}

The present study adopted an exploratory-descriptive and transversal method, with a quantitative approach. After signing the Data Use Consent Term and obtaining approval and consent from Faculdades Pequeno Príncipe $(2,692,293)$ and the Ethics Committee at Hospital Universitário Evangélico Mackenzie $(2,722,606)$, the data collection began.

The study sample was obtained through the analysis of the medical records of patients admitted to Hospital Universitário Evangélico Mackenzie (a reference center for neurosurgery), in the city of Curitiba, state of Paraná, Brazil, from February 2014 to December 2017, with a diagnosis of SAH caused by spontaneous cerebral aneurysm rupture. The initial sample consisted of 58 patients, and, after the first selection, 12 participants were excluded due to lack of information on the medical records or unavailable imaging exams.

First, the variables sex, age, vasospasm, death, clinical Hunt-Hess scale, Fisher and Modified Fisher radiological scales were subjected to a descriptive analysis. The frequency of each early death episode (up to 30 days of hospitalization) was assessed according to sex, age and vasospasm separately. Each scale was then analyzed separately regarding death and vasospasm.

Through the Logit model, the variable death was compared concomitantly with age, gender, hypertension, diabetes mellitus (DM), smoking, vasospasm, and the grades on the Hunt-Hess, Glasgow coma, and Fisher scales, followed by the comparison of death with the same variables, exchanging the Fisher scale with modified Fisher scale.

Finally, the odds ratio (OR) of each of the grades on the Fisher and modified Fisher scales was calculated to obtain the odds of the evolution into vasospasm.

The level of significance was set at $5 \%(p=0.05)$ for all statistical tests, and the software used was the TIBCO Statistica (TIBCO Software Inc, Palo Alto, CA, US), version 13.4.0.14.

\section{Results}

The analysis of medical records showed a prevalence of female individuals, corresponding to $69.5 \%(n=32)$ of the population studied, and individuals between 51 and 60 years of age, which is equivalent to $34.7 \%(n=16)$ of the sample. Vasospasm affected $39.1 \%(n=18)$ of the cases observed, $8(44.4 \%)$ of which died. Regarding early mortality (death within 30 days of hospitalization), 17 individuals (36.9\%) died, $76.4 \%(n=13)$ 
of which were female, as well as $35.2 \%(n=6)$ of individuals in the age range of 51 to 60 years. A $100 \%$ frequency was observed in patients classified as Hunt-Hess $5(n=4)$.The highest occurrence of this outcome happened in individuals classified as Fisher 3 (equivalent to $54.5 \% ; n=6$ ) and modified Fisher 4 (equivalent to $53 \% ; n=9$ ).

When analyzing the OR of the frequencies obtained, there was a greater tendency of evolution to vasospasm in patients classified as Fisher 3 (2.3 times higher than those of other grades).

To analyze the relationship between mortality and the other characteristics described in the present study, the logit model was applied, in which the variables age, gender, high blood pressure, DM, smoking, vasospasm, Hunt-Hess scale, Glasgow coma scale and Fisher grades 1, 2, 3 and 4 are concurrently analyzed. When observing the results of the model used, we understood that there is a relationship between the aforementioned factors and early mortality among the patients, with $80.43 \%$ of reproducibility to confirm this hypothesis in different population groups $(p=0.009)$.

In a second evaluation, the Fisher scale grades were replaced by modified Fisher 1, 2, 3 and 4 in the same logit model, to verify if there was a difference between the Fisher and modified Fisher scales as predictors of mortality. The interpretation of the data, when using the modified Fisher scale, showed that there was a relationship between death and the conditions analyzed concomitantly, with a reproducibility of $77.78 \%$ to confirm this hypothesis in different population groups $(p=0.01)$.

\section{Discussion}

On the one hand, the epidemiological results of the present study were very similar to those of previous studies, especially regarding the gender and the age of the patients: women were more affected, ${ }^{5-8}$ as well as individuals between 50 and 60 years of age. ${ }^{5-8}$ Some studies correlate the higher risk among women with the decrease in the levels of female hormones after menopause. .,9,10 $^{2}$

On the other hand, 58,6\% ( $n=27$ ) of our patients suffered from high blood pressure, against only $38 \%$ of the sample in another research. ${ }^{6}$ The same thing occurred with the smoking rate: $30.4 \%(n=14)$ of our patients were smokers, against $64.3 \%$ of the patients i another study. ${ }^{8}$ Both of these variables are considered risk factors for SAH. ${ }^{11}$

Regarding the grades of the patients at admission, there was no predominance of any grade on any of the scales.

As well as the epidemiological results, the mortality rate were very similar to that of another study, ${ }^{12}$ in which it was higher among patients aged between 50 and 60 years and those who were female. ${ }^{12}$ Althought some authors state that blood pressure does not increase the risk of death, 23,9\% $(n=11)$ of the patients with high blood pressure in the present trial died. For individuals who suffer from diabetes, the risk was lower than $15 \%$.

All patients classified as Hunt Hess 5 evolved to death, and the risk was directly proportional to the grade, such as in other studies. ${ }^{12,15}$ In line with other studies, in the present study the patients classified as modified Fisher 4 had the higher risk of death, ${ }^{3,12}$, as well as those classified as Fisher 3.

The OR proved that patients classified as Fisher 3 had the highest risk of evolution to vasospasm. ${ }^{3}$

There was no study in the literature comparing radiological scales with the risk of death. However, when considering all of those variables concomitantly, as the modified Fisher scale has $77.78 \%$ of reproducibility $(p=0.01)$, while the Fisher classification has $80 \%(p=0.009)$, when using the $\mathrm{OR}$, the evidence shows that Fisher 3 is better to predict this risk.

\section{Conclusion}

Our findings suggest that the risk of developing SAH is higher among women and people aged between 51 and 60 years. Among the pathologies, more than $50 \%$ ( $n=27$ ) of our patients suffered from high blood pressure. At admission, the most common grades were Fisher 4, modified Fisher 4 and HuntHess 2.

The patients who are more likely to evolve to death are women, those aged between 61 and 70 years, and those classified as Fisher 3, modified Fisher 4 and Hunt-Hess 5.

\section{Conflict of Interests}

The authors have no conflict of interests to declare.

\section{References}

1 Greenberg MS. In Manual de neurocirurgia. 5th edition. Porto Alegre: Artmed; 2003:728-773

2 Kloster R. [Subarachnoid hemorrhage in Vestfold county. Occurrence and prognosis]. Tidsskr Nor Laegeforen 1997;117(13): 1879-1882

3 Frontera JA, Claassen J, Schmidt JM, et al. Prediction of symptomatic vasospasm after subarachnoid hemorrhage: the modified fisher scale. Neurosurgery 2006;59(01):21-27, discussion 21-27

4 Hunt WE, Hess RM. Surgical risk as related to time of intervention in the repair of intracranial aneurysms. J Neurosurg 1968;28(01): $14-20$

5 Zamponi OZJ, et al. Analysis of intracranial aneurysms treated at a University Hospital in Curitiba. Arq Bras de Neurocirurgia 2012; 31(02):55-60

6 Choi JH, Park HS. The incidence and characteristics of patients with small ruptured aneurysms $(<5 \mathrm{~mm})$ in subarachnoid hemorrhage. J Korean Neurosurg Soc 2017;60(04):424-432

7 Santos Neto PH. Perfil clínico-epidemiológico dos pacientes com aneurismas intracranianos rotos tratados cirurgicamente em hospital universitário. Curitiba: Faculdade Evangélica do Paraná; 2017. Trabalho de conclusão de curso em Medicina.

8 Lasner TM, Weil RJ, Riina HA, et al. Cigarette smoking-induced increase in the risk of symptomatic vasospasm after aneurysmal subarachnoid hemorrhage. J Neurosurg 1997;87(03): 381-384

9 Johnston SC, Selvin S, Gress DR. The burden, trends, and demographics of mortality from subarachnoid hemorrhage. Neurology 1998;50(05):1413-1418

10 de Rooij NK, Linn FH, van der Plas JA, Algra A, Rinkel GJ. Incidence of subarachnoid haemorrhage: a systematic review with emphasis on region, age, gender and time trends. J Neurol Neurosurg Psychiatry 2007;78(12):1365-1372 
4 Spontaneous Subarachnoid Hemorrhage: Comparing Radiologic Scales Hanna et al.

11 Stegmayr B, Eriksson M, Asplund K. Declining mortality from subarachnoid hemorrhage: changes in incidence and case fatality from 1985 through 2000. Stroke 2004;35(09):2059-2063

12 Lantigua H, Ortega-Gutierrez S, Schmidt JM, et al. Subarachnoid hemorrhage: who dies, and why? Crit Care 2015;19:309

13 Claassen J, Vu A, Kreiter KT, et al. Effect of acute physiologic derangements on outcome after subarachnoid hemorrhage. Crit Care Med 2004;32(03):832-838
14 Wartenberg KE, Schmidt JM, Claassen J, et al. Impact of medical complications on outcome after subarachnoid hemorrhage. Crit Care Med 2006;34(03):617-623, quiz 624

15 Karamanakos PN, von Und Zu Fraunberg M, Bendel S, et al. Risk factors for three phases of 12-month mortality in 1657 patients from a defined population after acute aneurysmal subarachnoid hemorrhage. World Neurosurg 2012;78(06):631-639 